\title{
IDIOPATHIC MUSCULOSKELETAL PAIN AND STRESS FACTORS
}

The role of psychosocial factors was evaluated in 23 children with idiopathic musculoskeletal pain (IMP) and 52 with juvenile chronic arthritis (JCA), compared on admission and at 9 year follow-up, in a study at The National Hospital, Oslo, Norway. Patients with IMP had a higher prevalence of psychiatric diagnoses, school stress, and more chronic family difficulties and life events than those with JCA. (Aasland A, Flato B, Vandvik IH. Psychosocial factors in children with idiopathic musculoskeletal pain: a prospective, longitudinal study. Acta Paediatr July 1997;86;740-746). (Respond: Dr A Aasland, Division of Child and Adolescent Psychiatry, The National Hospital, Pilestredet 32, 0027 Oslo, Norway).

COMMENT. Children presenting with persistent so-called "growing pains" should receive a psychological work-up as part of the pediatric exam. It is hoped that this emphasis on emotional factors will not discourage the search for an organic cause of this sometimes distressing symptom.

\section{MOVEMENT DISORDERS}

\section{DYSMETRIC EYE MOVEMENTS IN TOURETTE SYNDROME}

A 13-year-old boy with an 11 year history of Tourette syndrome and progressively worsening tics, both motor and vocal, was referred to the Department of Ophthalmology, Great Ormond Street Hospital, London, because of visual symptoms and reading problems. He felt his eyes were crossing intermittently, but there was no diplopia and no strabismus. Refraction showed a mild hypermetropic astigmatism. Eye movement studies using electrooculography and simultaneous video recording showed dysmetric reflexive and voluntary saccades and failure of antisaccades, characteristic of disease of frontal lobes and basal ganglia. Visual symptoms resolved after spectacles were prescribed for the astigmatism, but reading difficulties were not benefited. (Narita AS, Shawkat FS, Lask B, Taylor DSI, Harris CM. Eye movement abnormalities in a case of Tourette syndrome. Dev Med Child Neurol April 1997;39:270-273). (Respond: Dr Chris Harris, Great Ormond Street Hospital for Children, London WC1N 3JH, UK).

COMMENT. Patients with Tourette disease may have an inability to form antisaccades, an abnormality of eye movements reflecting disease of the frontal lobes and basal ganglia.

\section{PIMOZIDE cf. HALOPERIDOL IN TOURETTE SYNDROME}

Pimozide (3.4 mg/day) and haloperidol (3.5 mg/day) therapy for Tourette syndrome were compared in a double-blind, 24-week, placebocontrolled crossover study of 22 patients, aged 7-16 years, at the Institute of Psychiatry, Charleston, SC. A $70 \%$ tic reduction was obtained in $64 \%$ of patients during either drug treatment, compared to $23 \%$ of patients with placebo. The effect of pimozide was significantly superior to that of placebo on total TS Global Scale scores, whereas the effect of haloperidol failed to reach statistical significance. Extrapyramidal side effects were more frequent with haloperidol than pimozide. Treatment-limiting side effects, depression, anxiety, severe dyskinesias, occurred in $41 \%$ of the 22 patients during haloperidol treatment, a threefold higher frequency than with pimozide. (Sallee FR, Nesbitt 1, Jackson C, Sine L, Sethuraman G. Relative efficiacy of haloperidol and pimozide in 